\title{
Pneumothorax in Neonates Born to COVID-19- Positive Mothers: Fact or Fortuity?
}

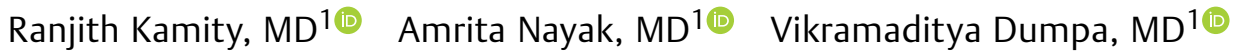 \\ 1 Division of Neonatology, Department of Pediatrics, NYU Langone \\ Hospital-Long Island, NYU Long Island School of Medicine, Mineola, \\ New York \\ Am J Perinatol Rep 2021;11:e49-e53.

\begin{abstract}
Address for correspondence Ranjith Kamity, MD, Division of Neonatology, Department of Pediatrics, NYU Langone Hospital-Long Island, NYU Long Island School of Medicine, 259 First Street, Mineola, NY 11501 (e-mail: ranjith.kamity@nyulangone.org).
\end{abstract}

\begin{abstract}
Keywords

- COVID-19

- coronavirus disease 2019

- neonate

- pneumothorax

- SARS-CoV-2

- vertical transmission

Neonates born to mothers with coronavirus disease 2019 (COVID-19) have been largely asymptomatic based on initial reports. All neonates born to mothers with COVID-19 have tested negative for severe acute respiratory syndrome coronavirus-2 (SARS-CoV2 ) in our institution (published data as of April 12, 2020). As novel presentations of COVID-19, such as multisystem inflammatory syndrome in children are being increasingly reported, we raise the possibility of increased incidence of pneumothorax in neonates born to SARS-CoV-2-positive mothers. Two recently described neonates with COVID-19 infection were noted to have pneumothoraces. We describe two SARS-CoV2-negative neonates born to COVID-19-positive mothers at 38 and 33 weeks, respectively, admitted to our neonatal intensive care unit for respiratory distress and subsequently developed pneumothoraces. As diverse clinical presentations in various age groups are being described, it becomes difficult to differentiate the increased incidence of complications related to an underlying illness, from COVID19-related illness. It remains to be seen if neonates with in utero exposure to SARSCoV-2 have an elevated inflammatory response with pneumonitis and exaggerated lung disease, similar to adult COVID-19 patients, due to in utero exposure.
\end{abstract}

Early reports show that neonates born to mothers with coronavirus disease 2019 (COVID-19) have been largely asymptomatic based on initial reports. ${ }^{1}$ All neonates born to mothers with COVID-19 in our institution have tested negative for severe acute respiratory syndrome coronavirus2 (SARS-CoV-2) (published data as of April 12, 2020). ${ }^{2}$ As novel presentations of COVID-19 such as multisystem inflammatory syndrome in children are being increasingly reported, ${ }^{3}$ we raise the possibility of increased incidence of pneumothorax in neonates born to SARS-CoV-2-positive mothers. Two recently described neonates with COVID-19 infection were noted to have pneumothoraces. ${ }^{4,5}$ A recent report also described two preterm infants born to SARS-CoV- 2-positive mothers presenting with pneumothoraces. ${ }^{6}$ We describe two SARS-CoV-2-negative neonates born to COVID19-positive mothers, who were admitted to our neonatal intensive care unit (NICU) for respiratory distress and subsequently developed pneumothoraces. Patient information was collected after obtaining parental consent for publication.

Case 1 is a 38 -week gestational age female born to a 36year-old mother with COVID-19 and rhinovirus infection via cesarean section for breech presentation. The infant was floppy at birth requiring positive pressure ventilation and was subsequently admitted to the NICU for respiratory distress. Initial chest X-ray performed while on nasal received

May 22, 2020

accepted after revision

January 14, 2021
DOI https://doi.org/

$10.1055 / \mathrm{s}-0041-1726020$. ISSN 2157-6998.

\footnotetext{
(C) 2021. The Author(s).

This is an open access article published by Thieme under the terms of the Creative Commons Attribution-NonDerivative-NonCommercial-License, permitting copying and reproduction so long as the original work is given appropriate credit. Contents may not be used for commercial purposes, or adapted, remixed, transformed or built upon. (https://creativecommons.org/ licenses/by-nc-nd/4.0/)

Thieme Medical Publishers, Inc., 333 Seventh Avenue, 18th Floor New York, NY 10001, USA
} 

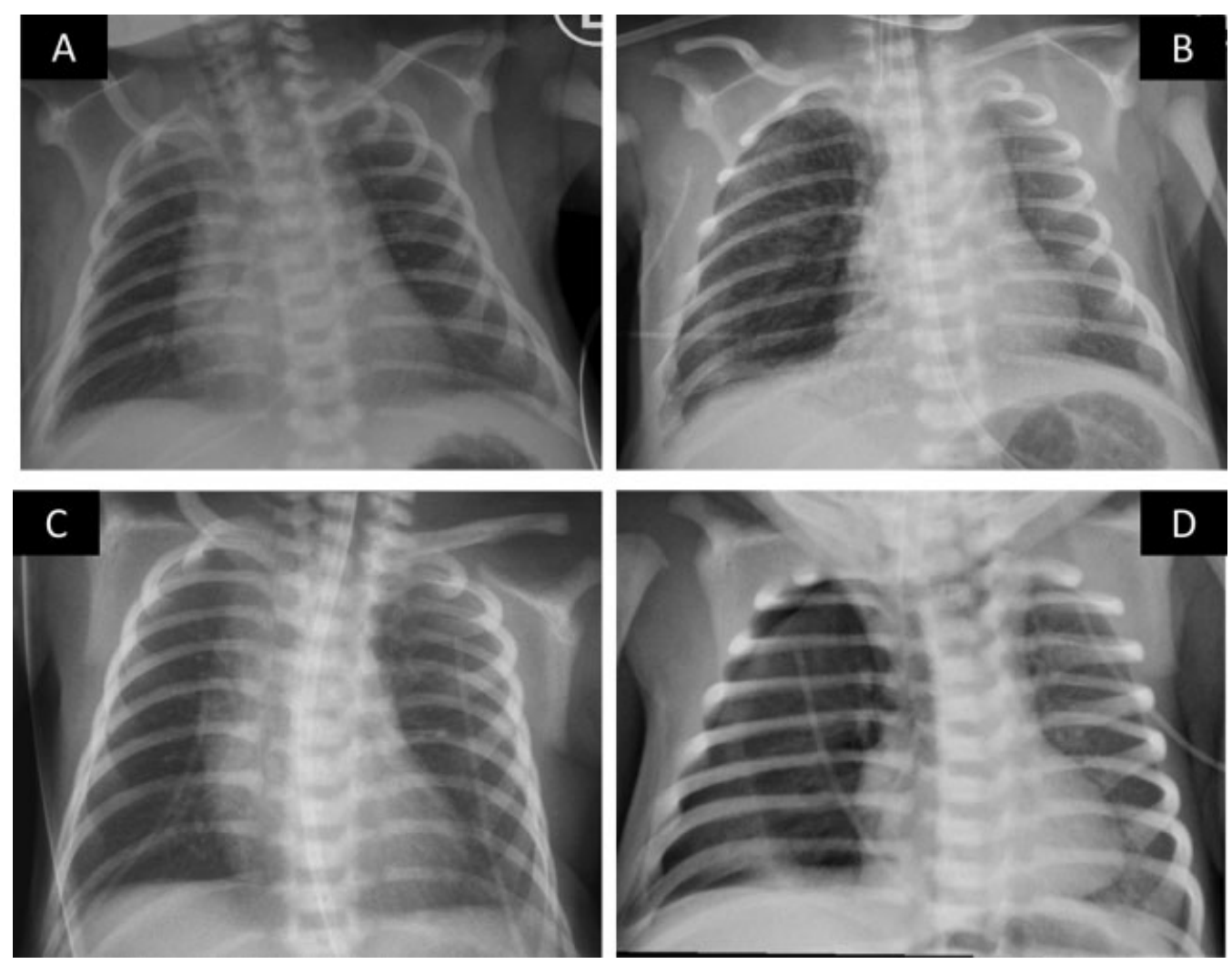

Fig. 1 Chest radiographs of both cases are shown here: Case 1: On admission (A) and when pneumothorax developed (B). This was confirmed as a moderate right pneumothorax on a decubitus view (image not shown). Case 2: On admission (C) and when pneumothorax developed (D).

continuous positive airway pressure (nCPAP) showed hazy lungs suggestive of respiratory distress syndrome (RDS) (-Fig. 1A). She was intubated uneventfully at 15 hours of life for worsening respiratory distress. A chest radiograph revealed a right-sided pneumothorax ( - Fig. 1B), which was treated using a tube thoracostomy. She was given intratracheal surfactant with improvement in the supplemental oxygen requirement. She was extubated on day of life (DOL) 6, weaned to room air on DOL13, and was discharged home on DOL19 uneventfully. Of note, she had elevated C-reactive protein (CRP) with negative blood and cerebrospinal fluid (CSF) cultures. Nasopharyngeal swabs for SARS-CoV-2 polymerase chain reaction (PCR) were negative at 24 hours and 5 days.

Case 2 is a 33-week gestational age preterm male born to a 26-year-old mother via cesarean section secondary to maternal COVID-19 pneumonia and acute respiratory failure. Prenatal course was previously uneventful. The infant did not require resuscitation at birth. He required nCPAP in the NICU with the initial chest X-ray suggestive of RDS (-Fig. 1C). Repeat chest X-ray for increased work of breathing on DOL1 showed a right-sided pneumothorax (-Fig. 1D). He was promptly intubated and the pneumothorax was treated using a tube thoracostomy. Intratracheal surfactant was also administered and the infant was extubated to nCPAP the following day. He was subsequently weaned to room air on DOL12 and was discharged home on DOL40. Nasopharyngeal swabs for SARS-CoV-2 PCR were negative at 24 and 48 hours. Details of the cases are included in -Table 1.

\section{Discussion}

Based on current recommendations, neonates born to mothers with suspected or confirmed COVID-19 and requiring NICU admission are ideally managed using airborne isolation precautions in a negative pressure room, pending SARS-CoV2 testing. ${ }^{7} 8$ If their SARS-CoV-2 PCR is negative, they may be moved out of negative pressure rooms to continue standard infection prevention precautions until discharge.

Neonatal pneumothorax is often multifactorial, with increased incidence in underlying lung diseases such as RDS, meconium aspiration, pneumonia, pulmonary hypoplasia, and those requiring respiratory support including nCPAP. While RDS is the most likely etiology for pneumothorax in neonates, case 1 was a full-term infant with RDS requiring nasal intermittent positive pressure ventilation followed by mechanical ventilation for 5 days, which was atypical for a full-term newborn. This infant also had bandemia and elevated CRP with negative blood and CSF cultures, and received antibiotic therapy for 7 days for clinical sepsis. Bacterial pneumonia cannot be ruled out in this infant with atypical chest radiograph findings. Maternal rhinovirus infection causing neonatal viral pneumonitis is highly unlikely.

The infant in case 2, although preterm at 33 weeks' gestation, had mild RDS requiring minimal nCPAP support (positive end-expiratory pressure $+5 \mathrm{~cm} \mathrm{H}_{2} \mathrm{O}$ and 0.21 fraction of inspired oxygen) and did not require positive pressure ventilation, which makes the occurrence of pneumothorax atypical. Neither infant had exposure to meconium. The rising CRP (as in 
Table 1 Patient characteristics and laboratory values for Cases 1 and 2

\begin{tabular}{|c|c|c|c|c|c|c|}
\hline Patient characteristics & \multicolumn{3}{|l|}{ Case 1} & \multicolumn{3}{|l|}{ Case 2} \\
\hline Gestational age & \multicolumn{3}{|l|}{$38 \mathrm{wk} 4 \mathrm{~d}$} & \multicolumn{3}{|l|}{$33 \mathrm{wk} 0 \mathrm{~d}$} \\
\hline Birth weight $(\mathrm{g})$ & \multicolumn{3}{|l|}{3,360} & \multicolumn{3}{|l|}{1,950} \\
\hline Sex & \multicolumn{3}{|l|}{ Female } & \multicolumn{3}{|l|}{ Male } \\
\hline Mode of delivery (indication) & \multicolumn{3}{|c|}{$\begin{array}{l}\text { Cesarean section (frank breech } \\
\text { presentation) }\end{array}$} & \multicolumn{3}{|c|}{$\begin{array}{l}\text { Cesarean section (maternal respiratory } \\
\text { failure) }\end{array}$} \\
\hline $\begin{array}{l}\text { Meconium-stained amniotic } \\
\text { fluid }\end{array}$ & \multicolumn{3}{|l|}{ No } & \multicolumn{3}{|l|}{ No } \\
\hline Resuscitation at delivery & \multicolumn{3}{|l|}{ PPV, CPAP } & \multicolumn{3}{|l|}{ None } \\
\hline APGAR ( 1 and 5 min) & \multicolumn{3}{|l|}{3,8} & \multicolumn{3}{|l|}{9,9} \\
\hline RDS (yes/no) & \multicolumn{3}{|l|}{ Yes } & \multicolumn{3}{|l|}{ Yes } \\
\hline $\begin{array}{l}\text { Baseline respiratory support } \\
\text { prior to pneumothorax }\end{array}$ & \multicolumn{3}{|c|}{$\begin{array}{l}\text { NIPPV (PEEP 6, PIP 20, Rate 30) } \mathrm{FiO}_{2} \text { : } \\
0.33\end{array}$} & \multicolumn{3}{|c|}{ nCPAP (PEEP 5) $\mathrm{FiO}_{2}: 0.21$} \\
\hline Umbilical lines & \multicolumn{3}{|c|}{$\begin{array}{l}\text { Yes (arterial and venous) } \\
\text { Inserted at } 17 \mathrm{~h} \text { of life }\end{array}$} & \multicolumn{3}{|l|}{ None } \\
\hline Age at pneumothorax & \multicolumn{3}{|l|}{$15 \mathrm{~h}$} & \multicolumn{3}{|l|}{$36 \mathrm{~h}$} \\
\hline Other comorbidities & \multicolumn{3}{|c|}{$\begin{array}{l}\text { Subtle nonsyndromic dysmorphic facial } \\
\text { features (wide nasal bridge) }\end{array}$} & \multicolumn{3}{|l|}{ None } \\
\hline \multicolumn{7}{|l|}{ Labs } \\
\hline $\begin{array}{l}\text { SARS-CoV-2 } \\
\text { (Performed using cobas } \\
\text { SARS-CoV-2 RT-PCR, Roche } \\
\text { Molecular Systems, Inc., } \\
\text { Pleasanton, CA) }\end{array}$ & \multicolumn{3}{|c|}{$\begin{array}{l}\text { (Nasopharyngeal) } \\
\text { Negative }(24 \mathrm{~h}) \\
\text { Negative }(5 \mathrm{~d})\end{array}$} & $\begin{array}{l}\text { (Nasophary } \\
\text { Negative (2 } \\
\text { Negative ( } 4\end{array}$ & & \\
\hline $\begin{array}{c}\text { Respiratory viral panel } \\
\text { (Film Array Respiratory Panel) }\end{array}$ & $\begin{array}{l}\text { Negative fo } \\
\text { rhinovirus }\end{array}$ & iple virus & uding & Negative & & \\
\hline CBC @ admission & & & & & & \\
\hline Hemoglobin $(\mathrm{g} / \mathrm{dL})$ & 14.8 & & & 19.1 & & \\
\hline Hematocrit (\%) & 46.7 & & & 54.2 & & \\
\hline Platelet count (per $\mu \mathrm{L}$ ) & 110,000 & & & 185,000 & & \\
\hline Total WBC (per $\mu \mathrm{L})$ & 7,100 & & & 17,800 & & \\
\hline Segmented neutrophils (\%) & 39 & & & 72 & & \\
\hline Bands (\%) & 0 & & & 0 & & \\
\hline Lymphocytes (\%) & 44 & & & 18 & & \\
\hline Monocytes (\%) & 7 & & & 10 & & \\
\hline Eosinophils (\%) & 8 & & & 0 & & \\
\hline Others (\%) & 2 & & & 0 & & \\
\hline $\begin{array}{l}\text { Blood gas (admit, before and } \\
\text { after CT) }\end{array}$ & Admission & Before & After & Admission & Before & After \\
\hline $\mathrm{pH}$ & $\begin{array}{l}A B G \\
7.33\end{array}$ & $\begin{array}{l}\text { CBG } \\
7.23\end{array}$ & $\begin{array}{l}\mathrm{ABG} \\
7.35\end{array}$ & $\begin{array}{l}\text { CBG } \\
7.27\end{array}$ & $\begin{array}{l}\text { CBG } \\
7.31\end{array}$ & $\begin{array}{l}A B G \\
7.33\end{array}$ \\
\hline $\mathrm{pCO}_{2}$ & 44 & 66 & 37 & 49 & 52 & 36 \\
\hline $\mathrm{pO}_{2}$ & 61 & 33 & 48 & 44 & 37 & 53 \\
\hline Bicarbonate & 23.2 & 23.6 & 20.4 & 22.5 & 26.2 & 19 \\
\hline Base excess & -3 & -2 & -5 & -5 & -1 & -6 \\
\hline Lactate & 1.7 & 2.4 & 2.7 & 3.5 & 2.2 & 5 \\
\hline CRP (mg/L) & $\begin{array}{l}9.90(12 \mathrm{~h}) \\
11.04(24 \mathrm{~h} \\
48.99(36 \mathrm{H}\end{array}$ & & & $0.63(36 \mathrm{~h}$ & & \\
\hline
\end{tabular}


Table 1 (Continued)

\begin{tabular}{|c|c|c|}
\hline Patient characteristics & Case 1 & Case 2 \\
\hline Blood culture & Negative & Negative \\
\hline Cerebrospinal fluid culture & Negative & Not done \\
\hline Head ultrasound & Connatal cysts & Normal \\
\hline MRI of the brain & $\begin{array}{l}\text { Connatal cysts, cavum septum pelluci- } \\
\text { dum; otherwise unremarkable newborn } \\
\text { MRI }\end{array}$ & None \\
\hline Miscellaneous laboratories & $\begin{array}{l}\text { Normal karyotype ( } 46 \mathrm{XX}) \\
\text { Chromosomal microarray: excess } \\
\text { homozygosities with no associated } \\
\text { syndromes }\end{array}$ & None \\
\hline \multicolumn{3}{|l|}{ Maternal characteristics } \\
\hline Age (y) & 36 & 26 \\
\hline Gravida/parity & $3 / 1$ & $2 / 0$ \\
\hline Prenatal course & Breech, otherwise uneventful & $\begin{array}{l}\text { Uneventful prior to maternal COVID-19 } \\
\text { infection }\end{array}$ \\
\hline $\begin{array}{l}\text { Abnormal ultrasound } \\
\text { findings }\end{array}$ & Suspected connatal cysts on fetal brain & None \\
\hline \multicolumn{3}{|l|}{ Prenatal laboratories } \\
\hline HIV & Negative & Negative \\
\hline Hepatitis B & Negative & Negative \\
\hline Rubella & Immune & Immune \\
\hline Syphilis & Nonreactive & Nonreactive \\
\hline GBS & Negative & Negative \\
\hline $\begin{array}{l}\text { SARS-CoV-2 } \\
\text { (Performed using Cepheid } \\
\text { Xpert Xpress SARS-CoV-2 RT- } \\
\text { PCR, Cepheid, Sunnyvale, CA) }\end{array}$ & Positive & Positive \\
\hline Respiratory viral panel & $\begin{array}{l}\text { Rhinovirus positive; negative for other } \\
\text { respiratory viruses }\end{array}$ & Negative for respiratory viruses \\
\hline Maternal COVID-19 course & Asymptomatic & $\begin{array}{l}\text { Pneumonia, acute respiratory failure, } \\
\text { recovered }\end{array}$ \\
\hline
\end{tabular}

Abbreviations: ABG, arterial blood gas; CBC, complete blood count; CBG, capillary blood gas; COVID-19, coronavirus disease 2019; CRP, C-reactive protein; $\mathrm{CT}$, chest tube; $\mathrm{DOL}$, day of life; $\mathrm{FiO}_{2}$, fraction of inspired oxygen; GBS, group B Streptococcus; nCPAP, nasal continuous positive airway pressure; NICU, neonatal intensive care unit; NIPPV, nasal intermittent positive pressure ventilation; PEEP, positive end-expiratory pressure; PIP, peak inspiratory pressure; PPV, positive pressure ventilation; RDS, respiratory distress syndrome; RT-PCR, reverse transcription polymerase chain reaction; SARS-CoV-2, severe acute respiratory syndrome coronavirus 2; WBC, white blood cells.

Note: This table describes the patient characteristics of both cases as well as laboratory values and relevant maternal information.

case 1) may also indicate the presence of inflammatory response akin to systemic inflammatory response syndrome which can activate an inflammatory cascade within the lung as with any other organ. The resulting acute respiratory distress syndrome can lead to intense lung inflammation with increased epithelial and endothelial permeability, edema, inflammatory exudates filling alveoli, surfactant dysfunction, and atelectasis potentially resulting in pneumothoraces.

Another hypothesis is that a drop in air pressure in the negative pressure room may contribute to increased risk in these infants on noninvasive respiratory support with underlying lung disease. The pressure change in a negative pressure room, however, is small in theory, and is not expected to cause a pneumothorax based on the limited knowledge available. Furthermore, such pressure differences would be further dampened, in theory, when infants are managed within isolettes inside negative pressure rooms. The infants reported here were also managed similarly and were placed in isolettes inside the negative pressure rooms pending SARS-CoV-2 testing. Nevertheless, while pneumothoraces are linked to underlying lung disease in otherwise sick neonates, their increased incidence in neonates potentially exposed to SARS-CoV-2 has to be considered.

\section{Conclusion}

As diverse clinical presentations in various age groups are being described, it becomes difficult to differentiate the increased incidence of complications related to an underlying illness, from COVID-19-related illness. It remains to be seen if neonates 
with in utero exposure to SARS-CoV-2 have an elevated inflammatory response with pneumonitis and exaggerated lung disease, similar to adult COVID-19 patients, due to in utero exposure. It is also unknown if increased use of invasive ventilation (for concerns of aerosolization) and limiting caregivers inside the isolation rooms (with potential for less monitoring) contribute to an increased incidence of complications in such neonates. Furthermore, false-negative tests in our neonates cannot be ruled out, given that patients have tested positive to SARS-CoV-2 on repeat testing, after testing negative initially. ${ }^{9}$ While preliminary literature implied low risk of vertical transmission, sporadic reports suggesting vertical transmission leading to neonatal SARS-CoV-2 infection are starting to accumulate. ${ }^{1,10-12}$ Thus, intrapartum viral exposure remains a strong possibility, as evidenced by positive SARSCoV-2 PCR from the fetal side of the placenta, especially in moderate to severe maternal COVID-19. ${ }^{12}$ Until larger studies can provide conclusive evidence, we advise increased vigilance in neonates born to COVID-19-positive mothers even when their SARS-CoV-2 PCR is negative.

\section{Authors' Contribution}

Ranjith Kamity conceptualized this manuscript and wrote the initial draft of the manuscript. Vikramaditya Dumpa and Ranjith Kamity obtained parental consent. All authors performed literature search, collected patient data, revised, reviewed, and accepted the final version of the manuscript as submitted.

\section{Financial Disclosure}

The authors have no financial relationships relevant to this article to disclose. No funding was secured for this manuscript.

\section{Conflict of Interest}

None declared.

\section{References}

1 Zeng L, Xia S, Yuan W, et al. Neonatal early-onset infection with SARS-CoV-2 in 33 neonates born to mothers with COVID-19 in Wuhan, China. JAMA Pediatr 2020;174(07):722-725

2 Vintzileos WS, Muscat J, Hoffmann E, et al. Screening all pregnant women admitted to labor and delivery for the virus responsible for coronavirus disease 2019. Am J Obstet Gynecol 2020;223(02): 284-286

3 Verdoni L, Mazza A, Gervasoni A, et al. An outbreak of severe Kawasaki-like disease at the Italian epicentre of the SARS-CoV-2 epidemic: an observational cohort study. Lancet 2020;395 (10239):1771-1778

4 Coronado Munoz A, Nawaratne U, McMann D, Ellsworth M, Meliones J, Boukas K. Late-onset neonatal sepsis in a patient with COVID-19. N Engl J Med 2020;382(19):e49

5 Piersigilli F, Carkeek K, Hocq C, et al. COVID-19 in a 26-week preterm neonate. Lancet Child Adolesc Health 2020;4(06): 476-478

6 Reddy A, Engelhardt K, Jain D. Air leak syndrome in two very preterm infants born to mothers with coronavirus disease 2019: an association or a coincidence? AJP Rep 2020;10(03):e266-e269

7 Chandrasekharan P, Vento M, Trevisanuto D, et al. Neonatal resuscitation and postresuscitation care of infants born to mothers with suspected or confirmed SARS-CoV-2 infection. Am J Perinatol 2020;37(08):813-824

8 Puopolo K, Hudak M, Kimberlin D, Cummings J. Initial Guidance: Management of Infants Born to Mothers with COVID-19. Accessed May 18, 2020 at: https://downloads.aap.org/AAP/PDF/ COVID\%2019\%20Initial\%20Newborn\%20Guidance.pdf

9 Woloshin S, Patel N, Kesselheim AS. False negative tests for SARSCoV-2 infection - challenges and implications. N Engl J Med 2020; 383(06):e38

10 Wang S, Guo L, Chen L, et al. A case report of neonatal 2019 coronavirus disease in China. Clin Infect Dis 2020. 28;71(15): 853-857

$11 \mathrm{Hu} X$, Gao J, Luo X, et al. Severe acute respiratory syndrome coronavirus 2 (SARS-CoV-2) vertical transmission in neonates born to mothers with coronavirus disease 2019 (COVID-19) pneumonia. Obstet Gynecol 2020;136(01):65-67

12 Penfield CA, Brubaker SG, Limaye MA, et al. Detection of severe acute respiratory syndrome coronavirus 2 in placental and fetal membrane samples. Am J Obstet Gynecol MFM 2020;2(03):100133 